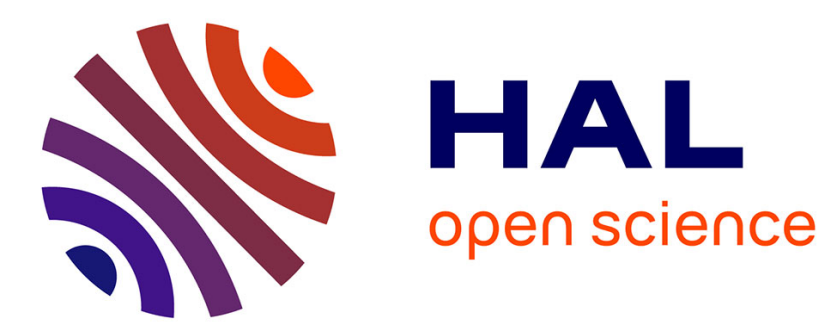

\title{
Understanding the reactivity of transition metal complexes involving multiple spin states
}

\author{
J Harvey, Rinaldo Poli, Kevin M. Smith
}

\section{To cite this version:}

J Harvey, Rinaldo Poli, Kevin M. Smith. Understanding the reactivity of transition metal complexes involving multiple spin states. Coordination Chemistry Reviews, 2003, 238-239, pp.347-361. 10.1016/S0010-8545(02)00283-7 . hal-03282836

\section{HAL Id: hal-03282836 \\ https://hal.science/hal-03282836}

Submitted on 19 Jul 2021

HAL is a multi-disciplinary open access archive for the deposit and dissemination of scientific research documents, whether they are published or not. The documents may come from teaching and research institutions in France or abroad, or from public or private research centers.
L'archive ouverte pluridisciplinaire HAL, est destinée au dépôt et à la diffusion de documents scientifiques de niveau recherche, publiés ou non, émanant des établissements d'enseignement et de recherche français ou étrangers, des laboratoires publics ou privés. 


\title{
Understanding the Reactivity of Transition Metal Complexes Involving Multiple Spin States
}

\author{
Jeremy N. Harvey \\ School of Chemistry, University of Bristol, Cantock's Close, Bristol BS8 ITS, U.K. \\ Rinaldo Poli \\ Laboratoire de Synthèse et d'Electrosynthèse Organométalliques, Université de Bourgogne, \\ Faculté de Sciences Gabriel, 6 boulevard Gabriel, 21000 Dijon, France \\ Kevin M. Smith \\ Department of Chemistry, University of Prince Edward Island, 550 University Avenue, \\ Charlottetown, PEI, Canada, C1A 4P3
}

\section{Abstract}

In coordination chemistry, many reactions involve several electronic states, in particular states of different spin. This phenomenon of "Multiple-State Reactivity" has been recognized for some time, both for gas-phase reactions of "bare" metal ions, and for transition metal complexes in solution. Until recently, however, much of the discussion of these systems has remained qualitative, because standard computational methods do not allow the location of the critical points for these processes, the Minimum Energy Crossing Points (MECPs) between states of different spin. Increased computational resources and new algorithms now enable MECPs to be located for large, realistic transition-metal containing systems, yielding important new insight into the mechanisms of important reactions such as oxidative addition of $\mathrm{C}-\mathrm{H}$ bonds to metal centers and ligand association/dissociation processes. Several examples will be presented for inorganic, organometallic and bioinorganic reactions.

\section{Keywords}

Coordination chemistry, organometallic chemistry, spin crossover, minimum energy crossing point, spin acceleration, two-state reactivity. 


\section{Table of Contents}

1. Introduction 3

2. Introductory example 4

3. Spin-Forbidden Steps in Iron-based Oxidation Chemistry 8

4. C-H bond Activation Chemistry 9

5. Polymerization Chemistry 14

6. Bio-inorganic Chemistry 16

$\begin{array}{ll}\text { 7. Conclusions } & 18\end{array}$

8. References 19 


\section{Introduction}

Unlike main-group compounds, transition metal complexes often have high-spin ground states, i.e. ones with several unpaired electrons. This occurs particularly often when the formal $d$-electron count on the metal is intermediate (e.g. 2 to 8 ), when the ligand field is weak due to the nature or the number of the ligands, and where $3 d$ elements are involved, due to the higher exchange interactions between compact $3 d$ orbitals. This means that even thermal chemical reactions of transition metal compounds are often "spin-forbidden", in that the reactants and products involved have a different overall electronic spin. In many areas of Chemistry, it has long been recognized that spin-forbidden processes actually occur rather frequently. In the limit of very strong spin-orbit coupling between the different states involved, such reactions in fact occur like any other ones, on a single adiabatic potential energy surface whose spin character varies smoothly from reactants to products. Where spin-orbit coupling is weaker, the reaction will behave in a non-adiabatic way (several electronic states are involved). There are several well-recognized examples of spin-forbidden processes: intersystem crossing and phosphorescence are very common in photochemistry,[1] spin-orbit mediated predissociation in spectroscopy,[2] and, in transition metal chemistry, spin crossover behavior. [3, 4] Nevertheless, the effect of spin changes on the kinetics of thermal reactions of transition metal compounds has not been well understood and in fact has been the object of relatively little discussion until fairly recently. Also, it has not been generally appreciated that a reaction transforming reactants in a given spin state into products with the same spin state may sometimes take place via intermediates having a different spin state. That is, the reaction coordinate may involve two (or more) spin surfaces. Part of the difficulty in recognizing this situation lies in the fact that reaction intermediates have a short lifetime and are not easily detected by spectroscopic techniques. The problem is accentuated when one looks at reactions involving diamagnetic reactants and products (a typical situation in organometallic chemistry) by NMR spectroscopy, a technique which reveals paramagnetic species only with much greater difficulty. Thus, this area of research can enormously benefit from the insights of computational chemistry.

Thanks to increased computer power and new algorithms, computational transition metal chemistry has matured into an invaluable aid to experimental work, as is amply demonstrated by the other articles in this issue and in other recent thematic surveys.[5, 6] However, the available methods for treating non-adiabatic reactions, and in particular reactions involving more than one spin state, are less well developed and less generally available. As a result, the bulk of computational reactivity studies concern single-surface (and often spin-singlet), adiabatic, processes. This is unfortunate, because transition metal chemistry is the field par excellence where multiple electronic states are encountered in thermal reactions. Of course, this has been well recognized for some time, and indeed computational studies have contributed to showing how prevalent spin changes are in this area. Simply, the opportunity to go beyond this qualitative recognition to derive a more quantitative level of insight has been missing by and large. In this review, we will survey a number of recent studies concerning spinforbidden reactions, and show how new algorithms are enabling an unprecedented level of 
understanding.

\section{Introductory Example}

To illustrate the problems and challenges involved in computational studies of spin-forbidden reactions, we will first of all discuss in some detail a system which has been a focus of considerable experimental and computational interest in one of our groups. Thus, the 17 electron complexes $\left[\mathrm{CpMoCl}_{2}\left(\mathrm{PR}_{3}\right)_{2}\right]$ have unexpectedly been found to undergo dissociative phosphine exchange in most cases. Most low-valent organometallic radicals instead undergo substitution through an associative process involving a 19-electron intermediate. The experimental observation that these Mo(III) compounds prefer to react via highly unsaturated 15-electron systems led to the suggestion by one of us[7] that a change of spin state occurs during the reaction, and actually favors the dissociative process. Given the existence and stability of 15 electron $\left[\mathrm{CpCrCl} 2\left(\mathrm{PR}_{3}\right)\right]$ with three unpaired electrons, the corresponding molybdenum system may also adopt a spin-quartet ground state and, provided the initial doublet complex can undergo a change of spin somewhere along the phosphine dissociative pathway, this should lead to a low-energy pathway for substitution. Efforts to isolate this unsaturated intermediate or models of it were, however, unfruitful, $[8,9]$ as were also attempts to observe it by spectroscopic methods.

The question then arose as to how computations could be used to substantiate this mechanism. First of all, density-functional theoretic (DFT) and wavefunction-based MP2 calculations on the dissociated model compound $\left[\mathrm{CpMoCl}_{2}\left(\mathrm{PH}_{3}\right)\right]$ confirmed that this intermediate does indeed have a quartet ground state,[10] with the doublet state lying some $2-6 \mathrm{kcal} / \mathrm{mol}$ higher, see Figure 1. Provided that the doublet and quartet surfaces cross in an energetically favorable region, spin-orbit coupling can be expected to lead to a substantially avoided crossing, so that the adiabatic potential surface evolves smoothly over a low barrier from the doublet 17 electron species to the quartet 15 -electron one. But how could one prove that this crossing did indeed occur in an energetically favorable region?

\section{$<$ Figure 1 $>$}

If this were a standard, spin-allowed process, one would merely need to locate the corresponding transition state. In principle, the same procedure could be used for a spin-forbidden reaction. When the full electronic Hamiltonian is used (i.e., including the spin-orbit coupling terms), the adiabatic energies obtained as a function of geometry by solving the electronic Schrödinger equation should lead to a surface involving a barrier near the avoided crossing of the zero-th order doublet and quartet states. However, this approach is barely practical with existing computational resources and programs, and certainly not using the available ab initio program packages generally used for problems involving transition metals. With these programs, systems of different spin correspond to different systems, which do not interact at all. Finding the region where the adiabatic wavefunction crosses from doublet to 
quartet is therefore equivalent to finding the points where the (non-interacting) corresponding potential energy surfaces cross. In fact, one is not merely looking for $a$ point where the two surfaces have the same energy. Two non-interacting molecular potential energy surfaces of dimension $3 \mathrm{~N}-6(\mathrm{~N}$ is the number of atoms involved) cross along a hypersurface of dimension $3 \mathrm{~N}-7$. The nearest approximation to the adiabatic transition state formed by avoided crossing is the point of minimum energy on this hypersurface, the minimum energy crossing point, or MECP. Of course, where spin-orbit coupling is strong, the adiabatic barrier may be somewhat lower in energy than the MECP due to the avoided crossing. This will need to be checked when codes become available to locate these transition states. At present, one can note that strong spin-orbit coupling introduces similar uncertainties to the energies of stationary points, so caution is needed anyway in considering computed potential energy surfaces for heavy metal systems. It is not obvious that MECPs will be significantly more affected than other points. In summary, MECPs provide a very valuable guideline to activation energies for spin flips, yet methods for locating them have unfortunately not been generally available.

It is to be noted that finding the MECP is not, strictly speaking, sufficient when studying reactivity problems. This is because one also needs to have some dynamical model for the rate of a reaction occurring through this crossing. When studying adiabatic reactions, one often uses the simplistic assumption that when two competing steps can occur, the faster reaction will be the one involving the lower-lying barrier. Some degree of extra sophistication can be attained by using approximate statistical mechanics to derive free energies rather than simply energies for the different transition states. In the case of spin-forbidden reactions of transition metal systems, an even more crude approximation can be made, whereby the spin-orbit coupling can be assumed to be large enough that the rate for reaction through an MECP should be similar to that through an adiabatic transition state of same energy. If necessary, a more sophisticated approach can be used, e.g. a non-adiabatic version of transition-state theory. $[11,12]$

Faced with the difficulty in finding MECPs, many computational studies of spin-forbidden processes have retreated to a qualitative discussion of the surface crossing. If one knows, for example, the relative energies of the different spin states at a representative number of stationary points on the individual surfaces, it is generally possible to estimate where the surfaces will cross. We will discuss some examples below which highlight how many studies have used this qualitative approach to good effect. There is however a difficulty with this procedure, which can be understood by comparison with transition states. In many cases, the position of transition states can be estimated from a good knowledge of the surrounding minima, e.g. by considering the difference in geometry between two linked minima, and the corresponding force constants. Indeed, before powerful routines to locate transition states became generally available, this type of argument was often used in computational studies of chemical reactivity. Obviously, though, there will be cases where this kind of qualitative approach is either not accurate enough, or indeed plain wrong. For this reason, very little work is published nowadays in which such a simple approach is used. Likewise, reasoning on surface crossings merely based on the stationary points will often be satisfactory, but will rarely bring quantitative insight, and will occasionally be misleading. 
Instead, many studies in this field have resorted to the use of what we have called the partial optimization method. This can be illustrated by considering the $\left[\mathrm{CpMoCl} 2\left(\mathrm{PR}_{3}\right)_{2}\right]$ system. [7, 13] Here, it is particularly obvious that the energies of the doublet and quartet states have a completely different dependence on one particular geometrical coordinate, namely the Mo-P distance. Thus, by carrying out partial geometry optimizations on both surfaces at a series of fixed values of this coordinate, an approximate crossing point can be found. We carried out these calculations, and found them to agree with experiment in that a crossing of the doublet and quartet surfaces was found in an energy regime compatible with dissociation of $\left[\mathrm{CpMoCl}_{2}\left(\mathrm{PR}_{3}\right)_{2}\right]$ to form quartet $\left[\mathrm{CpMoCl}_{2}\left(\mathrm{PR}_{3}\right)\right]$, at a lower energy than the competing spin-allowed ligand detachment, see Figure 2.

$<$ Figure 2 $>$

This ligand dissociation process is a relatively good example for treatment with the partial optimization method, essentially because the optimum values of the other geometric parameters in the two spin states are rather similar. Thus, the two partially optimized geometries for a given rMo-P are not too dissimilar. However, it should be emphasized that they do not match, so that one does not obtain a real "crossing point", which should lie somewhat higher in energy than the isoenergetic points on the two partial optimization curves. An estimated upper bound of the energy of the true MECP can be obtained by computing single-point energies of each spin state at both partially optimized geometries (e.g. point $(+)$ in Figure 2). In a situation where both lower and upper bound values lie below the reagent spin surface asymptote, it can be safely concluded that the reaction will involve a spin crossing. This was the case for the inversion of chirality at the metal centre in $[\mathrm{CpW}(\mathrm{NO})(\mathrm{CO})],[14]$ where the highest vertical excitation energy at the geometries having the same dihedral angle $\phi, 5.2 \mathrm{kcal} / \mathrm{mol}$, places the upper-bound value well below the singlet barrier of $16.1 \mathrm{kcal} / \mathrm{mol}$, see Figure 3 . For the example shown in Figure 2, however, a question remains as to the nature of the reaction as a one- or a two-state reaction and the exact location of the MECP becomes desirable.

$<$ Figure 3>

As will be discussed also further down, this partial optimization has been used very commonly in studies of spin-forbidden reactivity in transition metal chemistry. Because so many of the spinforbidden steps involve ligand dissociation, it is often easy to choose a suitable coordinate for the optimizations. However, as well as being of limited accuracy, as discussed above, we showed that the partial optimization technique is often rather expensive in computational terms compared to the exact location of the MECP. For this reason, we believe that the latter procedure is preferable in almost all cases.

Indeed, locating the MECP between two non-interacting surfaces exactly is a relatively easy 
mathematical operation.[15-19] In practical terms, one needs to provide some initial guess of the geometry of this point, and then compute the energies $V_{1}$ and $V_{2}$ and gradients on both surfaces. These can then be combined to generate an effective gradient:

$$
\mathbf{g}_{\text {eff }}=\left(V_{1}-V_{2}\right)\left[\left(\frac{\partial V_{1}}{\partial q}\right)-\left(\frac{\partial V_{2}}{\partial q}\right)\right]+\alpha\left\{\left(\frac{\partial V_{1}}{\partial q}\right)-\mathbf{h}\left[\left(\frac{\partial V_{1}}{\partial q}\right) \bullet \mathbf{h}\right]\right\}
$$

(Where $q$ are the atomic coordinates, $\mathbf{h}$ is a normalized vector parallel to the difference between the two gradients, $\left(\frac{\partial V_{1}}{\partial q}\right)-\left(\frac{\partial V_{2}}{\partial q}\right)$, and $\alpha$ is a parameter, with units of energy, chosen to make the magnitude of the two components of the effective gradient be roughly the same). The first term in this expression, the difference gradient, points towards the seam of crossing of the two surfaces, and the second points towards the minimum within the seam. Standard geometry optimization can then be used to search for points where this gradient goes to 0, which are MECPs. As with standard geometry optimization of minima, there is no guarantee that one will locate the global minimum on the seam in this way, so that several different MECPs may need to be located.

Using this procedure, an MECP was located for the $\left[\mathrm{CpMoCl}_{2}\left(\mathrm{PH}_{3}\right)\right]+\mathrm{PH}_{3}$ system,[13] with the structure shown in Figure 4. This has an Mo-P distance of $3.201 \AA$, considerably elongated with respect to the doublet minimum $\left(\mathrm{r}_{\mathrm{Mo}-\mathrm{P}}=2.580\right)$, and lies $12.1 \mathrm{kcal} / \mathrm{mol}$ above the minimum. This corresponds to $3.6 \mathrm{kcal} / \mathrm{mol}$ above the quartet dissociation asymptote, but $4.8 \mathrm{kcal} / \mathrm{mol}$ below the doublet asymptote. This result finally proved that the spin-forbidden dissociation is indeed kinetically and thermochemically favored over the spin-allowed route, confirming the initial hypothesis.

$<$ Figure $4>$

As can be guessed from the Fig. 2, the location of MECPs, as indeed the characterization of surface crossing by other means, is only meaningful if the theoretical method used for the two potential energy surfaces gives a fairly accurate description of their relative energetics. An extreme example of this requirement was given in ref. [19]. Thus the phenyl cation $\mathrm{C}_{6} \mathrm{H}_{5}{ }^{+}$has a singlet ground state with a triplet state ca. $20 \mathrm{kcal} / \mathrm{mol}$ higher; there is an MECP between singlet and triplet surfaces near the triplet minimum geometry. At the HF level of theory, the triplet is instead predicted to be the ground state, and an MECP is found close to the singlet minimum [19]. The need for an accurate treatment of relative energetics can be quite challenging for transition metal compounds, whose different spin states are frequently characterized by very different correlation (and exchange) energies, which can be poorly reproduced by many computational methods. This means that great care needs to be taken to calibrate ones computations to available experimental results. Overall, we have found that DFT, and in particular hybrid functionals such as B3LYP, give fairly good results in many cases.

After this introduction, we will proceed to discuss a variety of examples drawn from the literature, concerning spin-forbidden reactions of transition-metal compounds, and how computational chemistry 
has been able to participate in improving our understanding of them. The examples are drawn both from our own work and from other studies.

\section{Spin-Forbidden Steps in Oxidation Chemistry}

Much of the credit for bringing the present subject into the spotlight must surely be assigned to the "Two-State Reactivity" concept[20, 21] as put forward by Schröder, Schwarz and Shaik in a number of studies published since 1994. This concept originated from theoretical studies of a number of gas-phase reactions of small transition metal cations, and especially the reaction of the iron oxide cation, $\mathrm{FeO}^{+}$, with small molecules such as hydrogen. The $\mathrm{FeO}^{+}+\mathrm{H}_{2}$ reaction, leading to the formation of $\mathrm{Fe}^{+}$and water, has been studied experimentally by a number of research groups. Depending on the point of view, it is striking either for its rapidity or for its slowness. Thus, on the one hand, it is remarkably slow for a gas-phase reaction (roughly one collision out of 100 leads to products, [20] which is a very low efficiency for gas-phase ion-molecule reactions which frequently occur at the collisional rate). This is all the more striking because the reaction is formally spin-allowed, since the ground state of $\mathrm{FeO}^{+}$has a diradical-like, sextet electronic structure, and $\mathrm{Fe}^{+}$also has a sextet ground state.

As can be seen on the schematic potential energy surface of Figure 5, however, there is a significant barrier to the initial reaction, insertion of $\mathrm{FeO}^{+}$into the $\mathrm{H}-\mathrm{H}$ bond to form $\mathrm{HFeOH}^{+}$, on the sextet potential energy surface. This transition state lies $c a .8 \mathrm{kcal} / \mathrm{mol}$ above the energy of the reactants. Under the dilute gas-phase conditions of the experiments, the reactants are unlikely to be able to acquire this amount of energy, so that reactions over such high barriers should not occur. In this context, then, it is actually surprising that any collisions lead to reaction!

$<$ Figure 5 $>$

This is where the Two State Reactivity (TSR) concept intervenes: both $\mathrm{FeO}^{+}$and $\mathrm{Fe}^{+}$have relatively low-lying quartet excited states, as also shown on the Figure. Crucially, the barrier to insertion of $\mathrm{FeO}^{+}$into the $\mathrm{H}-\mathrm{H}$ bond is much lower on the quartet potential energy surface. To explain the observed reactivity, it is therefore necessary to assume that the sextet reactants cross over to the quartet potential energy surface in the vicinity of an MECP (shown as a heavy dot on the Figure) lying on the reactant side of the respective insertion TSs. Further rearrangement of the initial insertion intermediate occurs on the quartet potential energy surface, giving the quartet iron-water cationic complex. Somewhere near this point, an MECP with the lower-lying sextet surface may again occur, leading ultimately to the observed products, $\mathrm{Fe}^{+}$and water.

Although these authors have not specifically identified the MECPs involved, this description of the reactivity in this system provides cogent support for the idea that chemical reaction mechanisms frequently involve multiple spin states. Of course, gas-phase reactions of transition metal atoms or similar related species may seem very removed from ordinary coordination chemistry. In fact, many 
similar trends and phenomena can be identified in the two areas, so that the high level of information that can be obtained under the controlled conditions of the gas-phase is often very useful in interpreting condensed phase phenomena. As an example of this, the TSR predictions based on the $\mathrm{FeO}^{+}+\mathrm{H}_{2}$ model have been successfully used to rationalize some of the complex behavior observed in the biochemical reactivity associated with Compound I of cytochrome P450.[22-24] The Compound I intermediate in this oxidation enzyme contains a porphyrin core with an oxidized iron atom, formally $\mathrm{Fe}^{(\mathrm{V})}=\mathrm{O}$, whose reactivity in many ways parallels that of $\mathrm{FeO}^{+}$.

Several more recent computational studies have addressed the role of spin-forbidden steps in various other metal-catalyzed oxidations. The manganese-salen catalyst system of Jacobsen et al. has been a particular focus of attention, with a change in spin occurs during a key step [25]. A recent study has shown that epoxidation by $\left[\mathrm{Cp} * \mathrm{Cr}(\mathrm{O})(\mathrm{Cl})_{2}\right]$ is spin-forbidden, but locating the key MECP has enabled the authors to show that this does not affect reactivity [26]. Spin-changes were also studied, using a partial optimization technique, in an earlier study of chromyl chloride reactivity [27].

\section{C-H bond Activation Chemistry}

The activation of $\mathrm{C}-\mathrm{H}$ bonds remains one of the most attractive research areas in organometallic chemistry, holding promise for achieving a desirable selective functionalization of hydrocarbons. Although a variety of pathways in which transition metals interact with saturated hydrocarbons are possible (including atom transfer and $\sigma$-bond metathesis), the ubiquitous way in which $\mathrm{C}$-H bonds (and also $\mathrm{C}-\mathrm{C}$ bonds in a few favorable circumstances) are activated, as shown by the pioneering work of Bergman, Graham, Jones and others,[28-31] involves oxidative addition to coordinatively and electronically unsaturated (typically 16-electron), highly reactive intermediates. These intermediates are generated in situ by thermolytic or photolytic processes involving a ligand dissociation (typically CO) or a reductive elimination (typically $\mathrm{H}_{2}$ from a dihydride complex or a hydrocarbon from a hydridoalkyl complex). The high reactivity of these species does not allow in general their direct observation under normal conditions, although low temperature matrix isolation studies have been successful in a number of cases.[32] The spectroscopic observation of these species, either on-the-fly by ultrafast techniques or when matrix-isolated, has been limited in most cases to infrared spectroscopy. This yields at best indirect information on the spin state by comparison with computed vibrational frequencies. [33-35] An exception is provided by molybdenocene and tungstenocene, whose investigation by magnetic circular dicroism has in fact revealed its spin-triplet ground state.[36] On the other hand, it is known from the early work of Malcolm Green that these metallocenes, especially that of tungsten, undergo C$\mathrm{H}$ activation chemistry. [37, 38] Thus, it may be expected that other $\mathrm{C}-\mathrm{H}$ activation processes also take place via a multiple spin surface pathway.

The simple metallocenes of the heavy Group 6 metals, as well as variants of them where the two cyclopentadienyl rings are linked together via a bridge (termed ansa) have been the topic of extensive investigations. The 16-electron ansa systems undergo oxidative additions more readily than the regular metallocenes, whereas the reverse reductive elimination is more difficult. This phenomenon has been 
termed the "ansa effect".[39, 40] For example, while $\left[\mathrm{Cp}_{2} \mathrm{~W}(\mathrm{H})\left(\mathrm{CH}_{3}\right)\right]$ undergoes a facile transformation into $[\mathrm{Cp} 2 \mathrm{~W}(\mathrm{H})(\mathrm{Ph})]$ above $40^{\circ} \mathrm{C}$ in benzene, the ansa analogue $\left[\left\{\mathrm{CH}_{2}\left(\mathrm{C}_{5} \mathrm{H}_{4}\right)_{2}\right\} \mathrm{W}(\mathrm{H})\left(\mathrm{CH}_{3}\right)\right]$ resists the reductive elimination process at the benzene reflux temperature. Furthermore, photolysis of $\left[\left\{\mathrm{CH}_{2}\left(\mathrm{C}_{5} \mathrm{H}_{4}\right)_{2}\right\} \mathrm{MoH}_{2}\right]$ in benzene affords $\left[\left\{\mathrm{CH}_{2}\left(\mathrm{C}_{5} \mathrm{H}_{4}\right)_{2}\right\} \mathrm{Mo}(\mathrm{H})(\mathrm{Ph})\right]$, just like the non-ansa tungstenocene system, while the corresponding photolysis of $\left[\mathrm{Cp}_{2} \mathrm{MoH}_{2}\right]$ does not yield $\left[\mathrm{Cp}_{2} \mathrm{Mo}(\mathrm{H})(\mathrm{Ph})\right]$ (a non-existent compound), but rather a dinuclear product.

Computations by Jennifer Green by the partial optimization method, restricted to the two tungsten systems, have provided a first rationalization of this behavior (see Figure 6).[41] The internal coordinate chosen for this particular study was the W-C bond length. From this study, it is quite clear that the triplet tungstenocene is lowered in energy by the relaxation to the favored parallel ring structure, which is impossible in the bridged ansa complex. Qualitative considerations on the geometries of both spin states at the crossover point and on the vibrational frequencies led Green to propose that the crossover point shown in Figure 6(a) represents a close approximation of the real MECP, whereas the rigidity of the ansa system should provide an additional kinetic barrier to the loss of methane.

$<$ Figure 6>

More recent work, which includes the explicit location of the MECP and an extension to the Mo systems, provides a more complete rationalization of all experimental observations.[42] The results for the representative $\left[\mathrm{Cp}_{2} \mathrm{Mo}\right],\left[\mathrm{Cp}_{2} \mathrm{~W}\right]$ and $\left[\left\{\mathrm{CH}_{2}\left(\mathrm{C}_{5} \mathrm{H}_{4}\right)_{2}\right\} \mathrm{W}\right]$ systems are illustrated in Figure 7 . While the triplet molybdenocene is lower in energy than the singlet hydridomethyl derivative, in line with the non existence of the latter, the situation is reversed for the two (known) tungsten compounds. The intermediate $\eta^{2}$-methane complex shows a greater exothermicity and a smaller activation barrier toward methane oxidative addition for the ansa tungsten system relative to the non-ansa analogue. On the other hand, the barrier to $\mathrm{CH}_{4}$ loss (represented by the MECP), is located at a higher energy for the ansa system relative to the tungstenocene as predicted by Green. The overall barrier for methane loss from the hydromethyl complex is therefore much higher for the ansa system $\left(148.9 \mathrm{~kJ} \mathrm{~mol}^{-1}\right)$ than for the tungstenocene $\left(121.3 \mathrm{~kJ} \mathrm{~mol}^{-1}\right)$, in agreement with the experiment.

$<$ Figure $7>$

The magnetic state of other 16-electron complexes that are capable of oxidatively adding C-H bonds has not been determined directly. Therefore, computational chemistry remains the only available tool to assess the intervention of spin forbidden reactivity. A number of computational studies have assessed the spin state of the Group 9 16-electron [CPML] systems ( $M=$ Co, Rh, Ir; L = CO, phosphine),[43-50] for which experimental work has been extensive. For the $[\mathrm{CpM}(\mathrm{CO})]$ series, 
while the Rh species seems to possess a spin singlet ground state and the two states are nearly isoenergetic for iridium, Co seems to be much more stable as a triplet. This has been invoked as the reason for which $[\mathrm{CpCo}(\mathrm{CO})]$, unlike its heavier congeners, is unable to lead to $\mathrm{C}-\mathrm{H}$ activation chemistry.[46, 51] The energy and geometry of the crossing point has not been directly investigated in these cases. Siegbahn limited his study of the spin-forbidden addition of $\mathrm{CH}_{4}$ to triplet $[\mathrm{CpCo}(\mathrm{CO})]$ to the calculation of vertical excitation energies for the 16-electron $[\mathrm{CpCo}(\mathrm{CO})]$ complex itself and for the 18-electron $\eta^{2}$ complex. From a linear extrapolation of these excitation energies, he could arrive at an estimation of the spin crossover barrier.[46]

There have been many computational studies on $\left[\mathrm{CpIr}\left(\mathrm{PH}_{3}\right)\right]$ as a model of the $\left[\mathrm{Cp} * \operatorname{Ir}\left(\mathrm{PMe}_{3}\right)\right]$ system,[43, 47, 49, 50] given the relevance of this fragment to the mechanistic investigation of the C-H oxidative addition of various substrates. Whether calculations are carried out by HF-MP2 or by DFT, this fragment is found to possess a spin triplet ground state, the singlet being higher by some 15-35 kcal mol-1 $^{-1}$ depending on the computational method. These studies, however, do not address the details of the critical spin change or whether it is involved at all during the observed C-H activation chemistry. Indeed, depending on the shape of the different spin hypersurfaces, the MECP could lie below or above the reductive elimination singlet asymptote. We were intrigued by an experimental report by the Bergman group involving the interaction between $\left[\mathrm{Cp} * \mathrm{Ir}\left(\mathrm{PMe}_{3}\right)\right]$ and ethylene, the iridium fragment being generated by thermolysis of $\left[\mathrm{Cp} * \operatorname{Ir}\left(\mathrm{PMe}_{3}\right)(\mathrm{H})\left(\mathrm{C}_{6} \mathrm{H}_{11}\right)\right]$ at $160-180^{\circ} \mathrm{C}$. [52] The reaction provides a kinetically controlled 2:1 mixture of the hydridovinyl product of $\mathrm{C}-\mathrm{H}$ oxidative addition, $\left[\mathrm{Cp} * \operatorname{Ir}\left(\mathrm{PMe}_{3}\right)(\mathrm{H})\left(\mathrm{CH}=\mathrm{CH}_{2}\right)\right]$, and the $\pi$-addition complex, $\left[\mathrm{Cp} * \operatorname{Ir}\left(\mathrm{PMe}_{3}\right)\left(\mathrm{H}_{2} \mathrm{C}=\mathrm{CH}_{2}\right)\right]$. The elegant mechanistic work proves the involvement of an intermediate along the oxidative addition pathway and this intermediate must have all four ethylene $\mathrm{C}-\mathrm{H}$ bonds equally accessible to the $\mathrm{C}-\mathrm{H}$ oxidative addition. The $\pi$-addition complex is disqualified as an intermediate since this is the thermodynamically stable product; and no other obvious structure could be proposed for such species. Furthermore, it was not obvious to see at what level the partition among the two possible pathways would occur, as pointed out by a theoretical study which was unfortunately confined to the singlet spin surface.[53] Therefore, we wondered whether an explanation could be provided by a two-state pathway. Indeed, our investigation, [54] which included the exploration of MECPs, provides a picture which is consistent with all experimental observations (see Figure 8). In the entrance channel, the MECP is in fact calculated to lie slightly above the reductive elimination singlet asymptote. Since the barrier is very small and the spin-orbit coupling is substantial, however, the unimolecular collapse to the triplet ground state for the 16-electron $\left[\mathrm{CpIr}\left(\mathrm{PH}_{3}\right)\right]$ will be very fast and will predominate over the barrier-less but bimolecular addition of ethylene. A weak $\sigma$-complex $\left[\mathrm{CpIr}\left(\mathrm{PH}_{3}\right)\left(\cdots \mathrm{H}-\mathrm{CH}=\mathrm{CH}_{2}\right)\right]$ is likely to be the key intermediate. Just as proposed by Bergman (except for the critical fact that this is a triplet system), this intermediate has a low barrier for dissociative exchange of the $4 \mathrm{C}-\mathrm{H}$ bonds, which are therefore rendered equivalent in agreement with the prediction from the experimental isotope effects. Partition between the two pathways is then insured by a competition between crossover at the MECP which is near this intermediate (leading to the oxidative addition process) on one side, and rearrangement though a small barrier to a triplet $\eta^{1}$-ethylene complex (an $\mathrm{Ir}-\mathrm{CH}_{2} \mathrm{CH}_{2}$ diradical), on the other side. The latter intermediate then crosses over to the singlet surface directly or after 
rearrangement to a triplet $\eta^{2}-\mathrm{C}_{2} \mathrm{H}_{4}$ complex, in both cases leading to the singlet $\eta^{2}-\mathrm{C}_{2} \mathrm{H}_{4}$ product. The relative barriers are not in a perfect quantitative agreement with the observed product distribution, but the neglected steric effects of the $\mathrm{Cp}^{*}$ and $\mathrm{PMe}_{3}$ ligands can certainly play an important role at this level. However, locating MECPs does give for the first time a picture consistent with experiment which would have been difficult to achieve in any other way.

$<$ Figure $8>$

It is also worth briefly mentioning that the related Si-H oxidative addition of $\mathrm{Et}_{3} \mathrm{SiH}$ to 16-electron triplet species such as $\mathrm{CpMn}(\mathrm{CO})_{2}, \mathrm{CpV}(\mathrm{CO})_{3}, \mathrm{Fe}(\mathrm{CO})_{4}$ and $\mathrm{CpCo}(\mathrm{CO})_{2}$ is in fact faster than the corresponding addition to the related singlet species.[33-35] This phenomenon has been attributed to a greater tendency for the singlet species to establish $\sigma$ interactions with the ethyl $\mathrm{C}-\mathrm{H}$ bonds and be trapped in akyl-solvated intermediates which, for thermodynamic reasons, can not undergo $\mathrm{C}-\mathrm{H}$ oxidative addition. The triplet intermediates, on the other hand, do not interact with the ethyl moieties of triethylsilane and are thus free to form the final Si-H activated product via a spin crossover transition state. This proposed mechanism is supported by DFT calculations by the partial optimization method for the $\mathrm{M}_{-} \mathrm{SiH}_{3} \mathrm{CH}_{3}$ systems $\left[\mathrm{M}=\mathrm{CpV}(\mathrm{CO})_{3}, \mathrm{Fe}(\mathrm{CO})_{4}, \mathrm{CpCo}(\mathrm{CO})_{2}\right]$ with the metal-Si distance as the pivot parameter.[35]

An additional example where a spin change has been questioned in $\mathrm{C}-\mathrm{H}$ activation chemistry is provided by the $\mathrm{RhCl}(\mathrm{CO})\left(\mathrm{PR}_{3}\right)_{2}$ photocatalyst for hydrocarbon dehydrogenation. Both cis and trans isomers for the 14-electron $\mathrm{RhCl}\left(\mathrm{PR}_{3}\right)_{2}$ intermediate may adopt either a singlet or a triplet configuration and either spin state is predicted to be lower in energy depending on the computational method used.[55-59] Correlated methods, however, favor a singlet ground state in better agreement with the experimental results. Clearly, great care must be exercised in the selection of the computational technique for the investigation of two-state reactivity.

Finally, we would like to briefly mention some results concerning spin-forbidden chemistry in C-H bond activation during gas-phase reactions between "bare" metal atoms or ions with hydrocarbons. [60] Because bare metals or metal ions have high-spin ground states, insertion into $\mathrm{C}-\mathrm{H}$ bonds is often accompanied by a change in spin, and some of these steps have been studied in considerable detail, both computationally and experimentally. We will discuss two examples here: the addition of methane to the $\mathrm{Sc}^{+}$ion[61] and that of ethene to the $\mathrm{Zr}$ atom. [62] The former study appears to be, in fact, the first one with the explicit calculation of an MECP for a transition metal system. The scandium cation has a ${ }^{3} \mathrm{D}\left(\mathrm{s}^{1} \mathrm{~d}^{1}\right)$ ground state and its reaction with methane affords, as the ultimate products, spin singlet $\left({ }^{1} \mathrm{~A}_{1}\right) \mathrm{ScCH}_{2}{ }^{+}$and $\mathrm{H}_{2}$ when the reaction occurs at low energies. The results of the computational work are summarized in Figure 9.[61] The MECP calculation provided point XM in Figure 9, corresponding to a $\eta^{3} \mathrm{C}_{2 \mathrm{v}}$ structure, some $10 \mathrm{kcal} /$ mole above the $\mathrm{Sc}\left(\mathrm{CH}_{4}\right)^{+}$complex but still $13 \mathrm{kcal} / \mathrm{mole}$ below TS2. Therefore, the energetically most favorable mechanism involves initial addition to afford a triplet methane complex $\mathrm{Sc}\left(\mathrm{CH}_{4}\right)^{+}\left({ }^{3} \mathrm{~A}^{\prime}\right)$, then intersystem crossing at point XM and go over TS2 to yield the 
singlet hydridomethyl complex $\mathrm{HScCH}_{3}{ }^{+}\left({ }^{1} \mathrm{~A}^{\prime}\right)$. The reaction then continues on an endothermic channel giving the intermediate $\left(\mathrm{H}_{2}\right) \mathrm{ScCH}_{2}{ }^{+}$before $\mathrm{H}_{2}$ dissociation.

$<$ Figure 9>

The work on the $\mathrm{Zr}+\mathrm{C}_{2} \mathrm{H}_{4}$ reaction has not explicitly calculated MECP's.[62] The ground state of the metal atom is $4 \mathrm{~d}^{2} 5 \mathrm{~s}^{2}\left({ }^{3} \mathrm{~F}\right)$. The conclusion of this work is that the zirconacyclopropane intermediate along the triplet surface (1) in Figure 10) evolves in three possible manners as shown in the Figure: (i) back-scattering to the reactants; (ii) single-state (triplet) process over the ${ }^{3} \mathrm{TS}_{\text {ins }}$ barrier for insertion to yield $\mathrm{HZrC}_{2} \mathrm{H}_{3}$, followed by concerted $\mathrm{H}_{2}$ elimination to yield the acetylene complex $\mathrm{ZrC}_{2} \mathrm{H}_{2}$ in the triplet state; (iii) intersystem crossing leading, via the singlet zirconacyclopropane intermediate 5, to a stepwise process along the singlet surface, ending up in the singlet product. The two pathways leading to the product are shown as competitive. A fast intersystem crossing is argued on the basis of the similarity of the intermediates $\mathbf{1 b}$ and $\mathbf{5}$ in terms of geometries and energies.

$<$ Figure 10 $>$

The gas-phase reactivity of metal atoms and ions with hydrocarbons is an active area of research and a large number of additional results is expected in the near future. As many of the atoms investigated may exist in a multitude of spin states, it seems to us that the explicit investigation of MECPs will represent an important tool for this kind of research.

\section{Polymerization Chemistry}

The development of new single-site catalysts for the polymerization of olefins is a very active area of research in transition metal chemistry, especially for systems based on $\mathrm{d}^{0}$ Group 4 or $\mathrm{d}^{8}$ Group 10 catalysts. Computational studies of these diamagnetic systems have been undertaken by several groups, leading to an improved understanding of the fundamental steps of the polymerization process. [63] Systems that involve metals with an intermediate number of $\mathrm{d}$ electrons are potentially more complicated, as the overall reaction may proceed on more than one spin surface. Such systems have been investigated computationally much less frequently, and often such studies are limited to just one spin potential energy surface. Alternatively, two or more PESs may be examined without attempting to locate the MECPs between the surfaces. The following sections will examine recent computational work of these types in this area, as well as the more rare examples where the crossing points are explicitly located.

The most established class of single-site paramagnetic olefin polymerization catalysts are those based on quartet $\mathrm{d}^{3} \mathrm{Cr}(\mathrm{III})$, particularly those containing modified $\mathrm{Cp}$ ligands. [64] The binding and 
insertion of ethylene to a series of $\mathrm{d}^{3}\left[\mathrm{Cp}(\mathrm{L}) \mathrm{Cr}\left(\mathrm{CH}_{3}\right)\right]^{+}$model compounds (where $\mathrm{L}$ is a neutral ligand, either free or tethered to the Cp ring) were examined using DFT methods. [65] While this study helped account for the high polymerization activity achieved using $\mathrm{Cr}$ catalysts with tethered nitrogen-donor ligands, it was restricted to the quartet potential energy surface. A subsequent study on related tethered phosphorus-donor ligands also examined the excited doublet spin state, and suggested that spin crossover was important in the chain termination step, via $\beta$-hydrogen transfer from the growing polymer chain to bound ethylene.[66] A similar chain termination process assisted by spin pairing was also invoked in the theoretical study of non-Cp complexes of $\mathrm{Cr}$ (III) and V(III) with anionic chelating nitrogen-donor ligands. [67] In both cases, however, the MECPs for the spin inversion process were not located.

A recent theoretical study extended the examination of ethylene binding and insertion to a range of $\mathrm{M}(\mathrm{III})$ methyl cations $(\mathrm{M}=\mathrm{Sc}-\mathrm{Co})$ with tethered $\mathrm{N}$-donor Cp ligands.[68] A variety of spin states were calculated for $\mathrm{V}, \mathrm{Cr}, \mathrm{Mn}$ and $\mathrm{Fe}$, and while spin inversion was not explicitly investigated, it was conceded that crossing between PESs could influence the reactivity of all four of these metals, with the largest effect expected for Mn. A significant point addressed in this study was the differences between pure and hybrid DFT methods in evaluating the relative stability of different spin states. It had previously been observed that functionals like B3LYP that contain Hartree-Fock exchange generally favor high-spin states, while pure DFT functionals tend to favor low-spin states. Comparing the results of both DFT types and CASPT2 results for simplified Cr(III) catalyst models confirmed these tendencies, with more accurate results being achieved when the excited doublet state was corrected for spin contamination.[68]

For $\mathrm{d}^{3} \mathrm{Mo}(\mathrm{III})$, the relative energies of the quartet and doublet spin states are reversed compared to $\mathrm{Cr}(\mathrm{III})$. In a recent study,[69] one of us examined the polymerization activity of $\left[\mathrm{CpMo}\left(\eta^{4}-\right.\right.$ $\left.\left.\mathrm{C}_{4} \mathrm{H}_{6}\right)\left(\mathrm{CH}_{3}\right)\right]^{+}$model complexes, and showed that the polymerization process takes place on the doublet PES only. Although the MECP between the doublet and quartet PESs was located, the crossing point is higher in energy than the insertion transition state on the low spin surface, see Figure 11.

\section{$<$ Figure 11>}

While Cr-based polymerization catalysts have a longer history in both industrial and academic research, arguably the single-site paramagnetic systems with most commercial potential are those based on $\mathrm{Fe}$ (or $\mathrm{Co}$ ) bound to tridentate neutral N-donor ligands, with both DuPont and BP cross-licensing these technologies for commercial production in 1999.[70] Reported independently and nearly simultaneously by two groups in 1998, the dipyridylpyridine $\mathrm{d}^{6} \mathrm{Fe}$ (II) dichloro precursors have a quintet ground spin state. Depending on the degree of steric bulk in the ancillary ligands, these precursors form very highly active catalysts for olefin oligomerization or polymerization when activated with MAO.[71]

The Fe(II) system is also very computationally challenging, with two major studies having been 
reported to date.[72, 73] Both studies combined DFT and molecular mechanics techniques in order to model the entire ancillary ligand, since the bulky substituted aryl groups were required in order to obtain agreement with the experimental polymerization activity. Also important, however, are the three different PESs available for the $\mathrm{d}^{6} \mathrm{Fe}(\mathrm{II})$ species of interest: singlet, triplet and quintet. The first study used the BP86 functional (which does not contain a Hartree-Fock exchange term), and found that although the triplet state might be involved in the chain propagation process, the singlet state was the most important, with the quintet state lying too high in energy to be involved in polymerization. [72] A subsequent investigation used the hybrid B3LYP functional, and concluded that for the fully substituted model system, the singlet state was too high in energy, with the catalytic cycle remaining on the triplet and/or quintet PESs.[73] Reconciling this apparent discrepancy and locating the MECPs between the relevant PESs remain as targets for future investigations.

While the corresponding Co-based catalyst is slightly less active than the tridentate Fe system, its chemistry may be even more complex. A computational study conducted for the Co(II) system using BP86 was restricted to the doublet PES, although test calculations using hybrid DFT functionals led to enhanced relative stability of the quartet state.[74] This is consistent with the theoretical studies cited above for $\mathrm{Cr}(\mathrm{III})$ and $\mathrm{Fe}(\mathrm{II})$ polymerization catalysts. However, an additional degree of complication arises from recent experimental work $[75,76]$ that suggest that the catalytically active species may in fact be $\mathrm{d}^{6} \mathrm{Co}(\mathrm{III})$. This would require the computational investigation of the singlet, triplet, and quintet PESs as well, and the redox and spin crossover process that can interconvert these Co(III) and $\mathrm{Co}$ (II) species.

\section{Bio-inorganic Chemistry}

Spin-forbidden processes are particularly common for compounds of the first transition series, due to the high exchange constants between the $3 \mathrm{~d}$ electrons, and the compact nature of these orbitals, which leads to low overlap with ligand-based orbitals. In fact, this is especially true for the compounds of the transition elements in the right-hand part of the series. Iron is one of those metals, and given its ubiquity in bioinorganic chemistry, it is therefore not surprising that spin-forbidden chemistry is common in this area as well. In fact, an increasing number of experimental and computational studies have highlighted this aspect in recent years. One of the earliest applications of the "two-state reactivity" concept discussed earlier was in fact the oxidation chemistry of the cytochromes. Many recent studies [22-24] have shown that intermediates in these catalytic cycles can alternately have low- and high-spin ground states, so that spin-forbidden events must be particularly common. As well as these examples and that discussed below, many other bioinorganic reactions have been suggested to involve changes in spin. For example, binding of oxygen to deoxyhemocyanin involves a triplet to singlet transition, which has been studied for a model system by the partial optimization method [77].

In a recent study,[78] one of us has addressed in more detail another spin-forbidden process involving heme species. This is the recombination of small ligands such as $\mathrm{CO}, \mathrm{NO}$ or $\mathrm{O}_{2}$ with the imidazole-porphine systems found in the oxygen-transport proteins myoglobin and hemoglobin. [79] 
These reactions have been studied in great detail using a broad range of experimental techniques, so that they are probably among the most well understood biochemical processes. However, unlike many other bioinorganic reactions, there had been no previous computational modeling of the reaction mechanism.

The fundamental features of the potential energy surface are summarized in Figure 12. The hemebound ligands, with hexacoordinate iron, are usually the starting point for experimental studies. Laser photodissociation initiates the experiment, which leads, after rapid multi-surface excited-state dynamics, to a pentacoordinate heme state, with the ligand unbound, but confined to a small "pocket" within the protein (the geminate pair). At room temperature and above, the ligand can diffuse out of this pocket, as would be normal under the physiological conditions. At somewhat lower temperatures, however, this process is frozen out, and the competing recombination step returning to the starting point is instead sole observed. Various experimental techniques including flash photolysis with IR monitoring of the recombination, and ultrafast X-Ray diffraction, have been used to follow this whole process [80]. The kinetics of the recombination at low temperature have been the focus of the most interest, because it has been found that the decay of the geminate pair cannot be reproduced by a single exponential. This has been interpreted as meaning that the ensemble of different protein conformations making up "the" geminate pair are actually chemically different, with some recombining more rapidly, some more slowly. Additionally, the interconversion of the conformations must be slower at room temperature than the recombination, so that the overall transformation observed is in fact a combination of multiple "different" reactions. This is shown symbolically in Figure 12 by the three different curves for the recombination profile.

$<$ Figure $12>$

The focus here is however on a slightly different question, namely the origin of the barrier itself. As discussed above, the conformation of the protein has a strong influence on the height of the barrier, so it is perhaps natural to assume that the whole barrier is due to steric constraints upon the approach path of the ligand towards the metal atom. These constraints would naturally be dependent on the orientation of the side-chains making up the environment of the distal pocket. However, it has long been appreciated that the barrier may also have an underlying electronic origin. The ligand-free, 5coordinate iron(II) species in these proteins (e.g. deoxymyoglobin) are well known from experiment to have quintet electronic ground states. In contrast, the states with bound ligands (e.g. carbonmonoxymyoglobin and oxymyoglobin) have singlet ground states. Since $\mathrm{CO}$ is a singlet and $\mathrm{O}_{2}$ a triplet, recombination with both these ligands is spin-forbidden, and may involve an intrinsic "barrier" due to surface crossing between the high-spin geminate pair and the low-spin ligand-bound states. Although this has often been suggested,[81] no computational study previous to ours had characterized the surface crossing, due to the problems associated with spin-forbidden reactions. It was therefore unclear whether the first or the second of the causes discussed here is the origin of the experimentally observed 
activation energy.

\author{
$<$ Figure 13>
}

We have located MECPs between singlet, triplet and quintet surfaces for the model of the oxygencarrying center of globin proteins shown in Figure 13. In this model, the side-chains of the heme moiety have been omitted for computational convenience, and the proximal histidine which binds to the fifth coordination site is treated as an imidazole ligand. Because the protein environment is omitted from this model, steric effects will be inexistent in this system and only the intrinsic spin-forbidden surface crossing can lead to a barrier for recombination.

This is indeed what is found. A qualitative picture of the relation between the different states obtained at the B3LYP level of theory, using a polarized triple-zeta basis set, is also shown in Figure 13. It can be seen that the quintet surface is mainly repulsive, so that at the MECP with the attractive singlet surface, both states are ca. $2.5 \mathrm{kcal} / \mathrm{mol}$ higher in energy than the fragments in the ground, quintet state. The unspecified "reaction coordinate" in the Figure is mainly the $\mathrm{Fe}-\mathrm{C}$ bond length. However, the axis was deliberately not labeled as representing this coordinate, because a onedimensional picture is not really appropriate for this system. This is because the geometries of the quintet fragment and of the singlet minimum differ in many other, albeit somewhat less obvious, ways. For example, the iron atom, which lies very close to the plane of the porphyrin ring in the singlet state, both in the fragment and in the carbonyl complex, moves out of this plane by ca. $0.3 \AA$ in the quintet fragment. Even the rigid porphyrin system undergoes considerable changes in geometry from one spin state to another, with the $\mathrm{N}-\mathrm{N}$ distance across the ring changing by as much as $0.1 \AA$ between the quintet and singlet states. Using the partial optimization method with fixed $\mathrm{Fe}-\mathrm{C}$ distances would therefore not yield an accurate picture of the crossing behavior in this system, for the reasons discussed at the beginning of this review.

From this study, it is apparent that the spin-forbidden character of the recombination of CO with heme compounds is the source of an intrinsic barrier to the reaction, which is present even when the protein environment is absent. The magnitude of the computed barrier is in fair agreement with experimental values observed on proteins such as myoglobin.

\title{
7. Conclusions
}

In this review, we have discussed some of the many spin-forbidden reactions that occur in coordination chemistry. Important elementary steps such as ligand dissociation, oxidative addition, and migratory insertion can all involve a change in spin-state between reactants and products. Such steps are by no means "forbidden", because spin-orbit coupling mixes the zero-th order electronic wavefunctions to give adiabatic states which do not have a well defined spin. In the case where spinorbit coupling is strong, the system can occur entirely on a single potential energy surface, whose 
character varies smoothly as the reaction progresses, going for example from mainly "high-spin" in the reactant region to mainly "low-spin" for the products. In other cases where spin-orbit coupling is weaker, the reaction may have some non-adiabatic character. All in all, though, from the theoretical point of view, spin-forbidden reactions can be understood quite simply: If the avoided crossing between different spin states occurs low in energy, and spin-orbit coupling is substantial, the reaction will not be affected by the change in spin, with normal, "spin-allowed" barriers playing the dominant role. If instead the crossing occurs at higher energy, then there will be a supplementary barrier along the reaction profile, which may additionally be associated with a low transmission coefficient is spin-orbit coupling is small.

From the computational point of view, however, there is a serious problem in studying such reactions with the present electronic structure methods, which can usually only treat pure spin states, so cannot describe the spin-orbit coupling induced avoided crossings which play such an important part in reactivity. As a result, it is only possible to address the individual potential energy surfaces of different spin. Instead of locating avoided crossing and transition states, one needs to find out where these surfaces cross. We have discussed several examples in the review where researchers have characterized surface-crossing of this type in a qualitative way, and this can often allow one to distinguish between cases where spin-forbidden behavior does and does not play a large role in reactivity.

Where more quantitative insight is needed into reactivity, we believe we have made the case that the best approach is to locate the minimum energy crossing point (MECP) between the relevant potential energy surfaces. We have found that various more approximate techniques, especially the partial optimization approach, yield results of equal or inferior quality, and usually at higher computational expense. Locating MECPs is in fact rather easy, and codes for doing so are becoming more available.[82] We have highlighted several examples in this review of our own research, in which the location of MECPs has enabled some light to be shed on otherwise rather complex mechanistic questions. We are also aware of several other groups who are beginning to use these techniques to approach a range of interesting questions in the reactivity of transition metal complexes.

In conclusion, spin-"forbidden" reactions can end up being as fast as spin-allowed ones, or slower or faster! The devil is in the detail of how the potential energy surfaces cross, and we hope to have shown by this review that the tools for working this out are now available. In the past, mechanistic issues arising for reactions involving changes of spin have often been ignored, glossed over, or even misinterpreted. A much more quantitative approach is now possible.

\section{References}

1 J. Michl and V. Bonacic-Koutecký, 'Electronic Aspects of Organic Photochemistry', WileyInterscience, 1990.

$2 \quad$ D. R. Yarkony, J. Phys. Chem. 100 (1996) 18612-18628.

3 P. Gütlich, Y. Garcia and T. Woike, Coord. Chem. Rev. 219 (2001) 839-879. 
P. Gütlich, Y. Garcia and H. A. Goodwin, Chem. Soc. Rev. 29 (2000) 419-427.

E. R. Davidson (Guest Editor), 'Computational Transition Metal Chemistry', Chem. Rev. 100 (\#2) (2000).

T. R. Cundari (Editor) 'Computational Organometallic Chemistry', 2001.

A. A. Cole, J. C. Fettinger, D. W. Keogh and R. Poli, Inorg. Chim. Acta 240 (1995) 355366.

F. Abugideiri, D. W. Keogh, H.-B. Kraatz, R. Poli and W. Pearson, J. Organomet. Chem. 488 (1995) 29-38.

J. C. Fettinger, D. W. Keogh and R. Poli, J. Am. Chem. Soc. 118 (1996) 3617-3625.

I. Cacelli, D. W. Keogh, R. Poli and A. Rizzo, J. Phys. Chem. A 101 (1997) 9801-9812.

J. N. Harvey and M. Aschi, Phys. Chem. Chem. Phys. 1 (1999) 5555-5563.

J. C. Lorquet and B. Leyhnihant, J. Phys. Chem. 92 (1988) 4778-4783.

K. M. Smith, R. Poli and J. N. Harvey, New J. Chem. 24 (2000) 77-80.

K. M. Smith, R. Poli and P. Legzdins, Chem. Eur. J. 5 (1999) 1598-1608.

N. Koga and K. Morokuma, Chem. Phys. Lett. 119 (1985) 371-374.

A. Farazdel and M. Dupuis, J. Comput. Chem. 12 (1991) 276-282.

D. R. Yarkony, J. Phys. Chem. 97 (1993) 4407-4412.

M. J. Bearpark, M. A. Robb and H. B. Schlegel, Chem. Phys. Lett. 223 (1994) 269-274.

J. N. Harvey, M. Aschi, H. Schwarz and W. Koch, Theor. Chem. Acc. 99 (1998) 95-99.

S. Shaik, D. Danovich, A. Fiedler, D. Schröder and H. Schwarz, Helv. Chim. Acta 78 (1995) 1393-1407.

D. Schröder, S. Shaik and H. Schwarz, Acc. Chem. Res. 33 (2000) 139-145.

S. Shaik, M. Filatov, D. Schröder and H. Schwarz, Chem. Eur. J. 4 (1998) 193-199.

M. Filatov, N. Harris and S. Shaik, Angew. Chem. Int. Ed. 38 (1999) 3510-3512.

F. Ogliaro, N. Harris, S. Cohen, M. Filatov, S. P. deVisser and S. Shaik, J. Am. Chem. Soc. 122 (2000) 8977-8989.

C. Linde, B. Akermark, P.-O. Norrby and M. Svensson, J. Am. Chem. Soc. 121 (1999) 5083-5084. See, however: Y. G. Abashkin, J. R. Collins and S. K. Burt, Inorg. Chem. 40 (2001) 4040-4048.

J. S. Hess, S. Leelasubcharoen, A. L. Rheingold, D. J. Doren and K. H. Theopold, J. Am. Chem. Soc. 124 (2002) 2454-2455.

M. Torrent, L. Q. Deng and T. Ziegler, Inorg. Chem. 37 (1998) 1307-1314.

A. H. Janowicz and R. G. Bergman, J. Am. Chem. Soc. 104 (1982) 352-354.

J. K. Hoyano and W. A. G. Graham, J. Am. Chem. Soc. 104 (1982) 3723-3725.

W. D. Jones and F. J. Feher, J. Am. Chem. Soc. 104 (1982) 4240-4242.

R. G. Bergman, J. Organomet. Chem. 400 (1990) 273-282.

V. E. Bondybey, A. M. Smith and J. Agreiter, Chem. Rev. 96 (1996) 2113-2134.

H. Yang, M. C. Asplund, K. T. Kotz, M. J. Wilkens, H. Frei and C. B. Harris, J. Am. Chem. Soc. 120 (1998) 10154-10165.

P. T. Snee, H. Yang, K. T. Kotz, C. K. Payne and C. B. Harris, J. Phys. Chem. A 103 (1999) 10426-10432.

P. T. Snee, C. K. Payne, K. T. Kotz, H. Yang and C. B. Harris, J. Am. Chem. Soc. 123 (2001) 2255-2264.

P. A. Cox, P. Grebenik, R. N. Perutz, M. D. Robinson, R. Grinter and D. R. Stern, Inorg. Chem. 22 (1983) 3614-3620.

C. Giannotti and M. L. H. Green, J. Chem. Soc., Chem. Commun. (1972) 1114-1115.

N. J. Cooper, M. L. H. Green and R. Mahtab, J. Chem. Soc., Dalton Trans. (1979) 15571562 .

L. Labella, A. Chernega and M. L. H. Green, J. Chem. Soc., Dalton Trans. (1995) 395-402. A. Chernega, J. Cook, M. L. H. Green, L. Labella, S. J. Simpson, J. Souter and A. H. H. Stephens, J. Chem. Soc., Dalton Trans. (1997) 3225-3243. 
J. C. Green and C. N. Jardine, J. Chem. Soc., Dalton Trans. (1998) 1057-1061.

J. C. Green, J. N. Harvey and R. Poli, J. Chem. Soc, Dalton Trans. (2002) 1861-1866.

T. Ziegler, V. Tschinke, L. Fan and A. D. Becke, J. Am. Chem. Soc. 111 (1989) 9177-9185.

J. Song and M. B. Hall, Organometallics 12 (1993) 3118-3126.

D. G. Musaev and K. Morokuma, J. Am. Chem. Soc. 117 (1995) 799-805.

P. E. M. Siegbahn, J. Am. Chem. Soc. 118 (1996) 1487-1496.

R. Jiménez-Cataño and M. B. Hall, Organometallics 15 (1996) 1889-1897.

M.-D. Su and S.-Y. Chu, Organometallics 16 (1997) 1621-1627.

M.-D. Su and S.-Y. Chu, J. Phys. Chem. A 101 (1997) 6798-6806.

M.-D. Su and S.-Y. Chu, Chem. Eur. J. 5 (1999) 198-207.

A. A. Bengali, R. G. Bergman and C. B. Moore, J. Am. Chem. Soc. 117 (1995) 3879-3880.

P. O. Stoutland and R. G. Bergman, J. Am. Chem. Soc. 107 (1985) 4581-4582.

J. Silvestre, M. J. Calhorda, R. Hoffmann, P. O. Stoutland and R. G. Bergman, Organometallics 5 (1986) 1841-1851.

K. M. Smith, R. Poli and J. N. Harvey, Chem. Eur. J. 7 (2001) 1679-1690.

M. R. A. Blomberg, P. E. M. Siegbahn and M. Svensson, J. Am. Chem. Soc. 114 (1992) 6095-6102.

N. Koga and K. Morokuma, J. Am. Chem. Soc. 115 (1993) 6883-6892.

P. Margl, T. Ziegler and P. E. Blöchl, J. Am. Chem. Soc. 117 (1995) 12625-12634.

P. Margl, T. Ziegler and P. E. Blochl, J. Am. Chem. Soc. 118 (1996) 5412-5419.

J. S. Bridgewater, T. L. Netzel, J. R. Schoonover, S. M. Massick and P. C. Ford, Inorg. Chem. 40 (2001) 1466-1476.

K. Eller and H. Schwarz, Chem. Rev. 91 (1991) 1121-1177.

D. G. Musaev and K. Morokuma, J. Phys. Chem. 100 (1996) 11600-11609.

M. Porembski and J. C. Weisshaar, J. Phys. Chem. A 105 (2001) 4851-4864.

S. Q. Niu and M. B. Hall, Chem. Rev. 100 (2000) 353-405.

K. H. Theopold, Eur. J. Inorg. Chem. (1998) 15-24.

V. R. Jensen, K. Angermund and P. W. Jolly, Organometallics 19 (2000) 403-410.

A. Dohring, V. R. Jensen, P. W. Jolly, W. Thiel and J. C. Weber, Organometallics 20 (2001) 2234-2245.

L. Q. Deng, R. Schmid and T. Ziegler, Organometallics 19 (2000) 3069-3076.

V. R. Jensen and W. Thiel, Organometallics 20 (2001) 4852-4862.

E. Le Grognec and R. Poli, Chem. Eur. J. 7 (2001) 4572-4583.

A. H. Tullo, Chem. \& Eng. News 79 (2001 (Oct. 22nd)) 38-39.

S. D. Ittel, L. K. Johnson and M. Brookhart, Chem. Rev. 100 (2000) 1169-1203.

L. Deng, P. Margl and T. Ziegler, J. Am. Chem. Soc. 121 (1999) 6479-6487.

D. V. Khoroshun, D. G. Musaev, T. Vreven and K. Morokuma, Organometallics 20 (2001) 2007-2026.

P. Margl, L. Deng and T. Ziegler, Organometallics 18 (1999) 5701-5708.

V. C. Gibson, M. J. Humphries, K. P. Tellmann, D. F. Wass, A. J. P. White and D. J. Williams, Chem. Commun. (2001) 2252-2253.

T. M. Kooistra, Q. Knijnenburg, J. M. M. Smits, A. D. Horton, P. H. M. Budzelaar and A. W. Gal, Angew. Chem., Int. Ed. Engl. 40 (2001) 4719-4722.

M. Metz and E. I. Solomon, J. Am. Chem. Soc. 123 (2001) 4938-4950.

J. N. Harvey, J. Am. Chem. Soc. 122 (2000) 12401-12402.

For a recent experimental paper on this reaction, containing extensive references to previous work, see ref. [80].

V. Šrajer, Z. Ren, T. Y. Teng, M. Schmidt, T. Ursby, D. Bourgeois, C. Pradervand, W.

Schildkamp, M. Wulff and K. Moffat, Biochemistry 40 (2001) 13802-13815.

H. Frauenfelder and P. G. Wolynes, Science 229 (1985) 337-345.

82 The code developed by one of the authors $(\mathrm{JNH})$, which can be used in conjunction with a 
variety of electronic structure packages such as gaussian and jaguar, is freely available to interested researchers. 


\section{Captions for Figures}

Figure 1. Relative total energies for B3LYP-geometry-optimized $\mathrm{CpMoCl}_{2}\left(\mathrm{PH}_{3}\right)+\mathrm{PH}_{3}$ and $\mathrm{CpMoCl}_{2}\left(\mathrm{PH}_{3}\right)_{2}$ systems. Data are taken from ref. [10].

Figure 2. Energies of partially optimized doublet and quartet relative to the overall doublet minimum, at various $\mathrm{C} \mathrm{pMoCl}_{2}\left(\mathrm{PH}_{3}\right)_{2}$ fixed $\mathrm{Mo}-\mathrm{P}$ distances, including dissociated $\mathrm{CpMoCl}_{2}\left(\mathrm{PH}_{3}\right)$ (dashed lines) and estimated upper limit of the crossing point energy (+). Reproduced with permission from ref. [13]. Copyright 2000 Royal Society of Chemistry.

Figure 3. Energies of optimized $[\mathrm{CpW}(\mathrm{NO})(\mathrm{CO})]$ at various fixed dihedral N-W-CNT-C angles. Reproduced with permission from ref. [14]. Copyright 1999 Wiley-VCH.

Figure 4. Optimized geometry of the MECP between doublet and quartet $\mathrm{CpMoCl}\left(\mathrm{PH}_{3}\right)_{2}$.

Figure 5. Schematic high-spin (sextet) and low-spin (quartet) potential energy surfaces for the gasphase reaction of $\mathrm{FeO}^{+}$with $\mathrm{H}_{2}$. (Adapted from ref. [20]).

Figure 6. Energies of triplet and singlet $C_{2 v}$ methane complexes (a) $\left[\mathrm{W}\left(\eta_{-}-\mathrm{C}_{5} \mathrm{H}_{5}\right)_{2}\left(\mathrm{CH}_{4}\right)\right]$ and (b) $[\mathrm{W}\{(\eta$ $\left.\left.\mathrm{C}_{5} \mathrm{H}_{4}\right)_{2} \mathrm{CH}_{2}\right\}\left(\mathrm{CH}_{4}\right)$ ] at varying $\mathrm{W}-\mathrm{C}$ distance with respect to the energy of the corresponding methyl hydride. Reproduced with permission from ref. [41]. Copyright 1998 Royal Society of Chemistry.

Figure 7. Reaction coordinate for the $\mathrm{CH}_{4}$ oxidative addition to $\mathrm{Cp}_{2} \mathrm{Mo}$ (left), $\mathrm{Cp}_{2} \mathrm{~W}$ (center) and $\left[\mathrm{CH}_{2}\left(\mathrm{C}_{5} \mathrm{H}_{4}\right)_{2}\right] \mathrm{W}$ (right). All energies are at the B3LYP/LANL2DZ level. Adapted from ref. [42].

Figure 8. Schematic drawing showing the four MECPs between singlet and triplet potential energy surfaces, and thereby the two-state pathway leading from singlet $\left[\mathrm{CpIr}\left(\mathrm{PH}_{3}\right) \mathrm{H}\left(\mathrm{CH}_{3}\right)\right]$ to singlet $\left[\mathrm{CpIr}\left(\mathrm{PH}_{3}\right) \mathrm{H}\left(\mathrm{CH}=\mathrm{CH}_{2}\right)\right]$ or singlet $\left[\mathrm{CpIr}\left(\mathrm{PH}_{3}\right)\left(\eta^{2}-\mathrm{CH}=\mathrm{CH}_{2}\right)\right]$ via triplet [CpIr $\left.\left(\mathrm{PH}_{3}\right)\right]$. Relative energies in $\mathrm{kcalmol}^{-1}$. Reproduced with permission from ref. [54]. Copyright 2001 Wiley-VCH.

Figure 9. Potential energy profiles of the reaction $\mathrm{ScCH}_{2}{ }^{+}+\mathrm{H}_{2}$. Reproduced with permission from 
ref. [61]. Copyright 1996 American Chemical Society.

Figure 10. Schematic of lowest energy triplet and singlet reaction paths based on $m$ PW1PW91 energetics, including three parallel, competitive decay rates from the triplet metallacyclopropane complex 1b. Reproduced with permission from ref. [62]. Copyright 2001 American Chemical Society.

Figure 11. Energy diagram and key structures for the ethylene insertion reaction into the $\mathrm{M}-\mathrm{CH}_{3}$ bond of $\left[\mathrm{CpMo}\left(\eta^{4}-\mathrm{C}_{4} \mathrm{H}_{6}\right)\left(\mathrm{CH}_{3}\right)\right]^{+}(\mathrm{d}=$ spin doublet; $\mathrm{q}=$ spin quartet $)$. Reproduced with permission from ref. [69]. Copyright $2001 \mathrm{Wiley-VCH.}$

Figure 12. Qualitative potential energy surface for reaction of a heme protein such as myoglobin $(\mathrm{Mb})$ with a small ligand such as CO.

Figure 13. Computational model for the deoxy-globin proteins and approximate potential energy curves. Reproduced with permission from ref. [78]. Copyright 2000 American Chemical Society. 
Figure 1

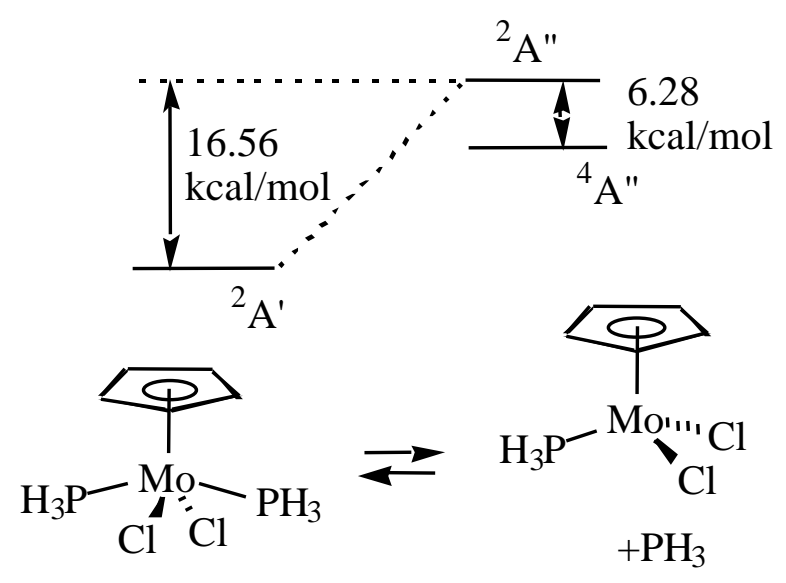

Figure 2

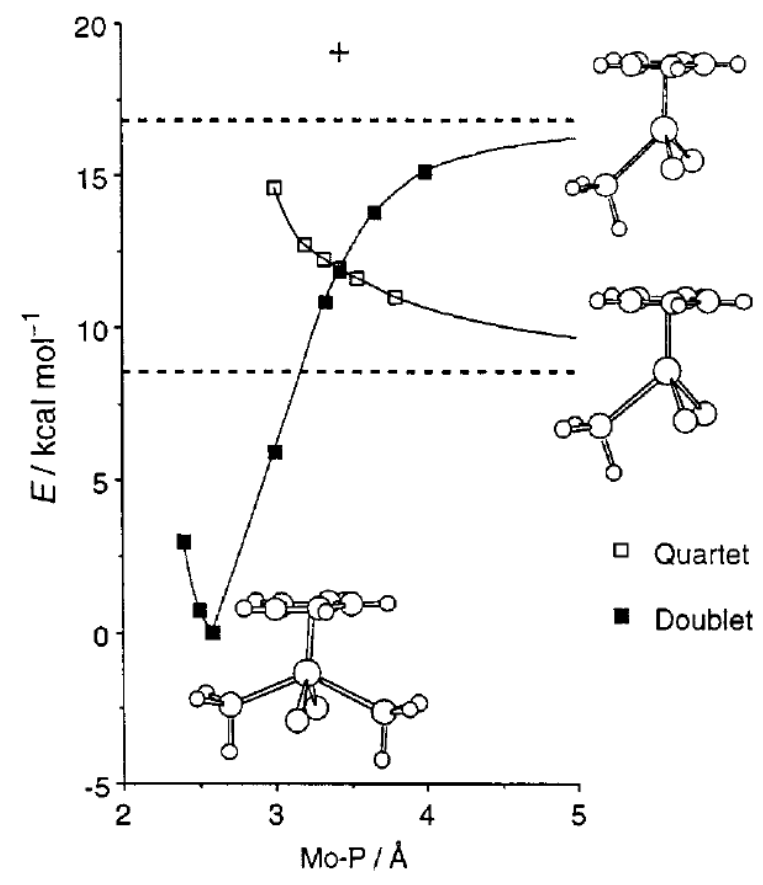


Figure 3

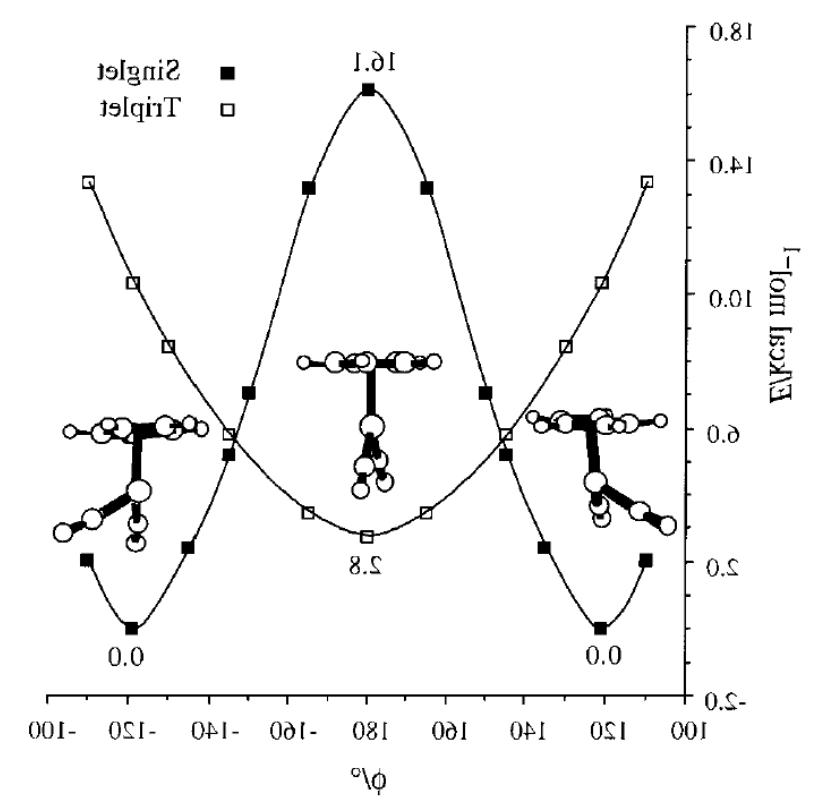

Figure 4

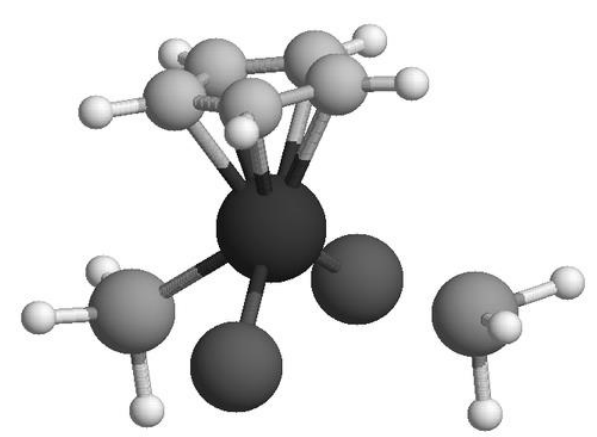


Figure 5

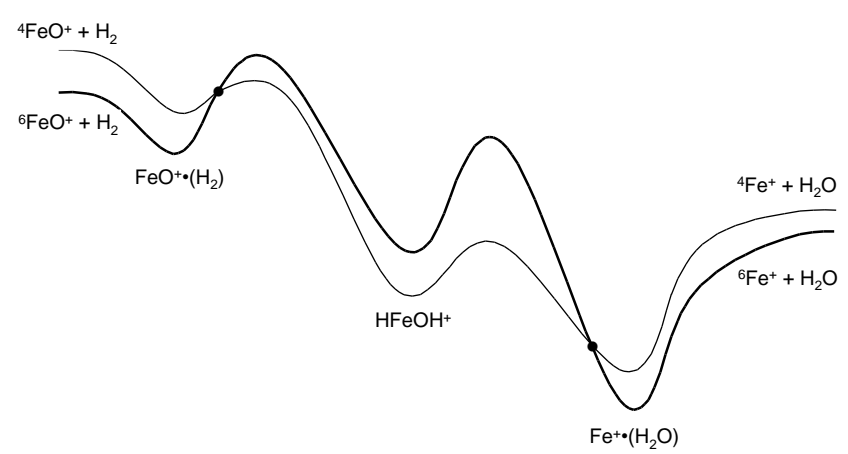

\section{Figure 6}

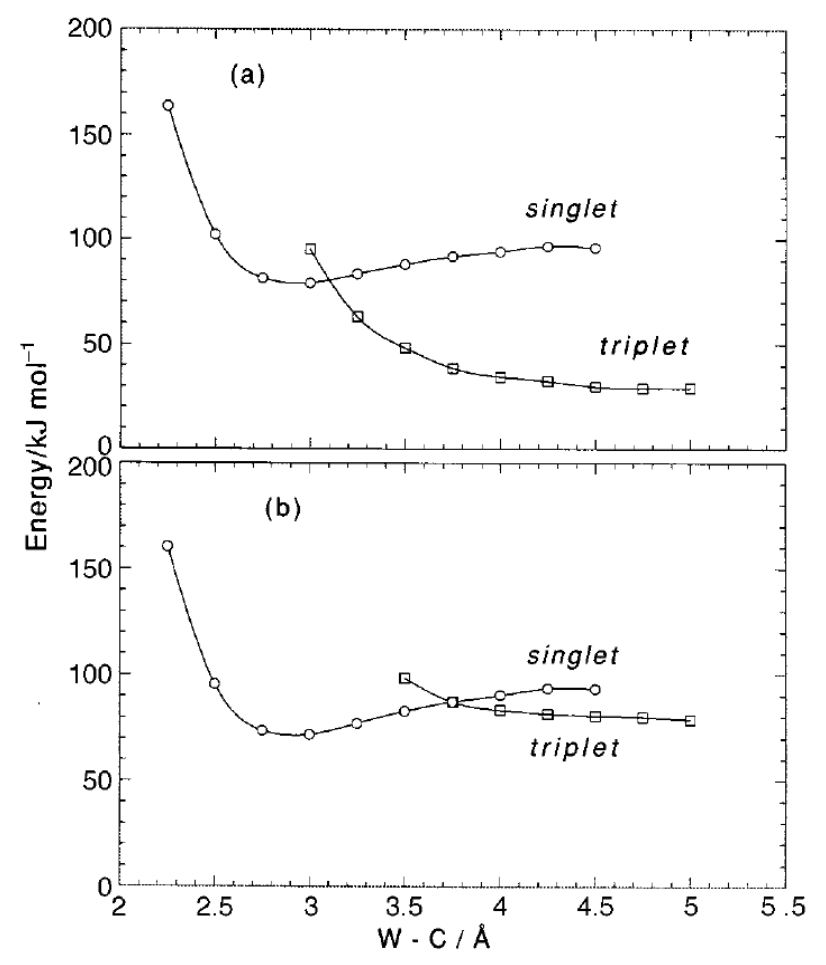

Figure 7
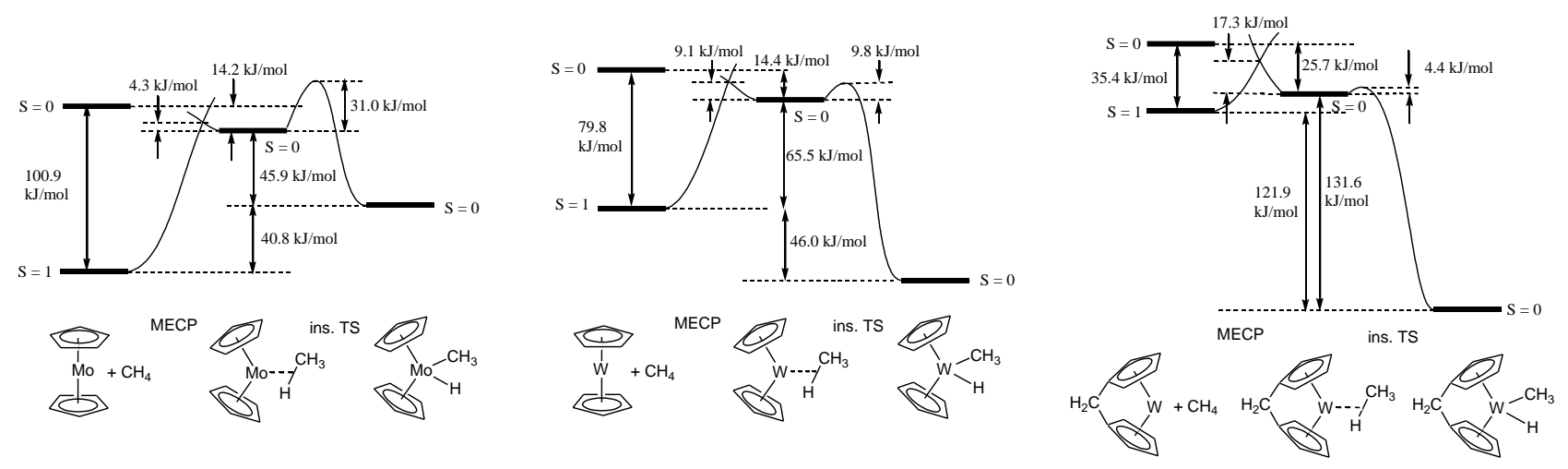


\section{Figure 8}

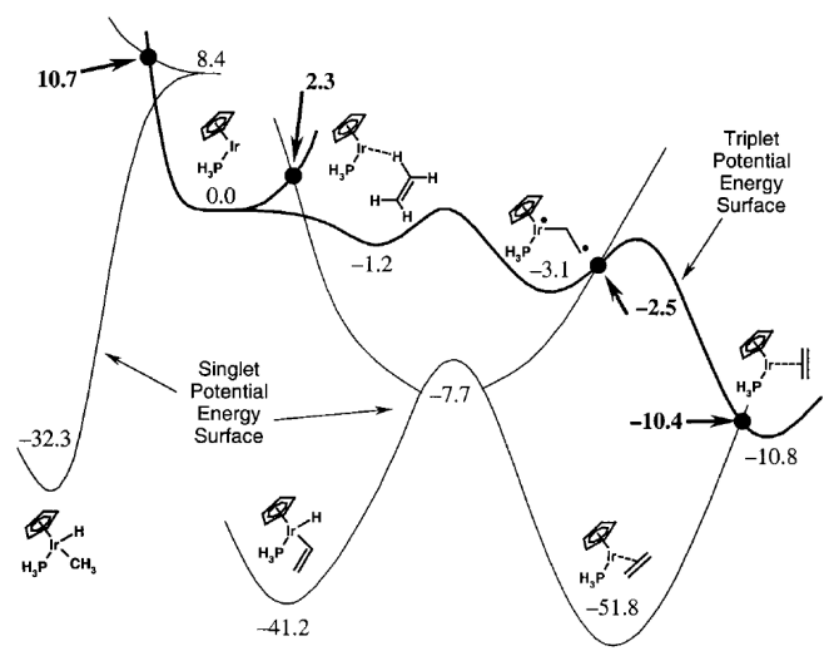

\section{Figure 9}

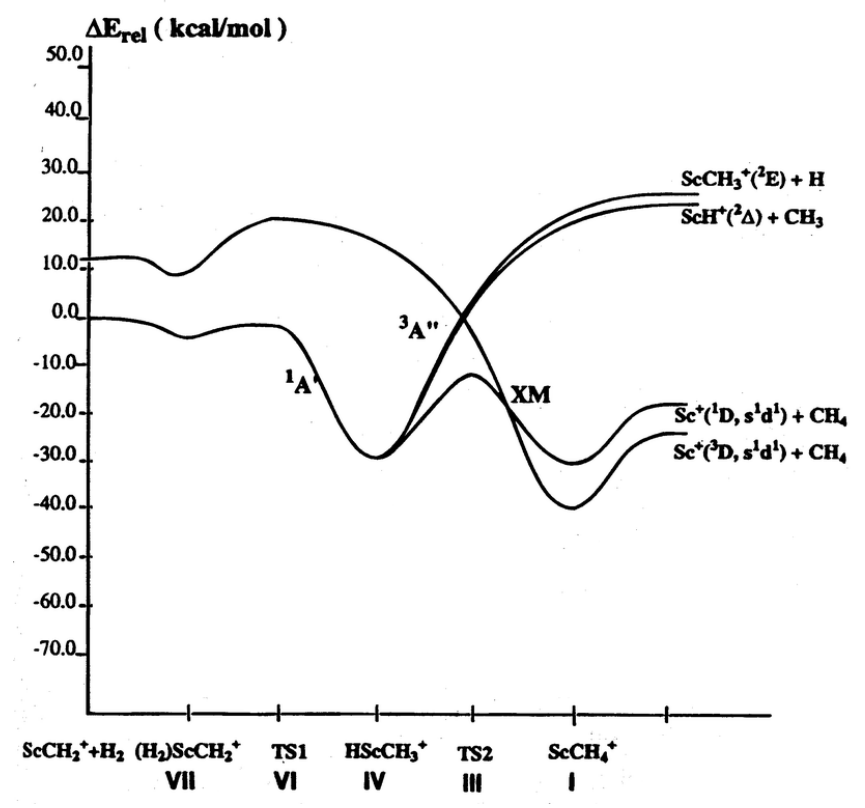


Figure 10

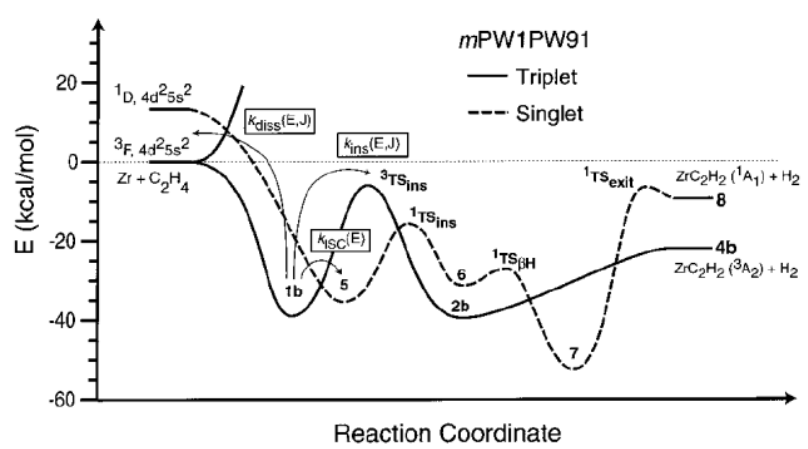

Figure 11

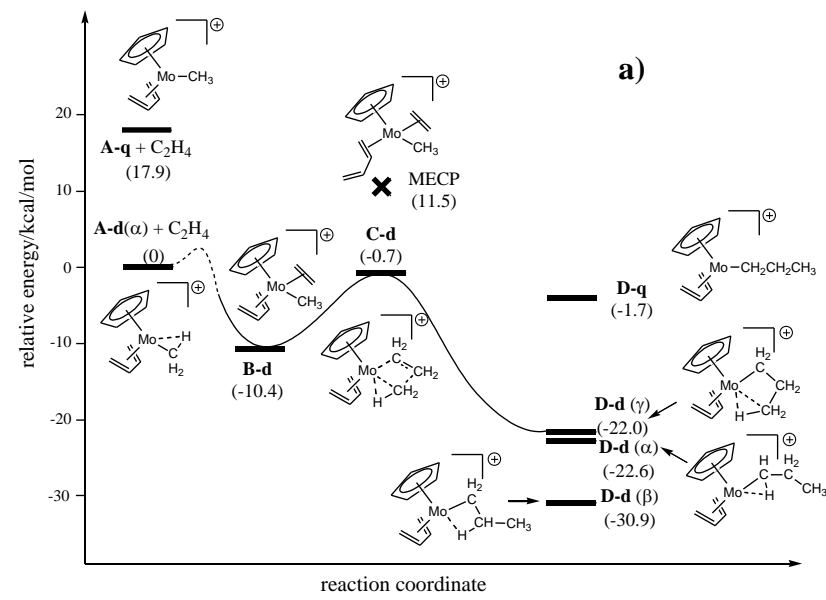




\section{Figure 12}

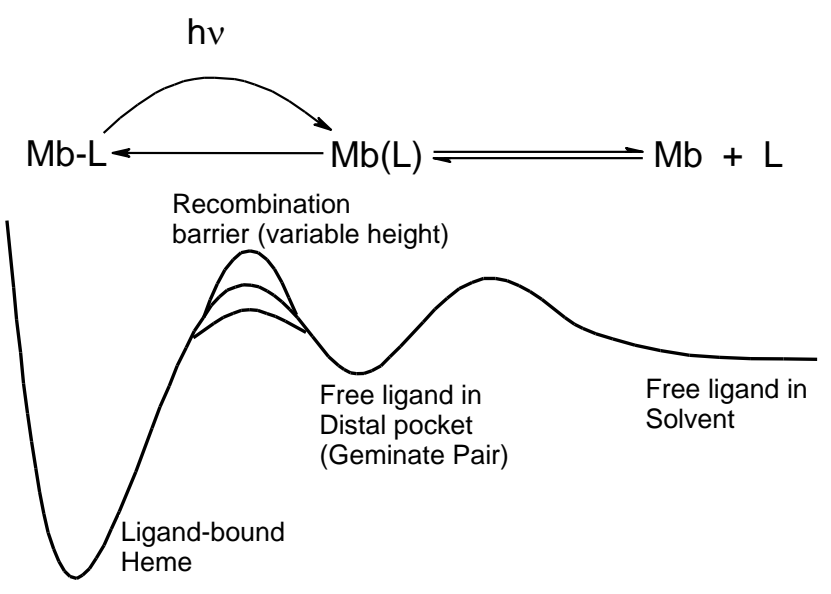

\section{Figure 13}

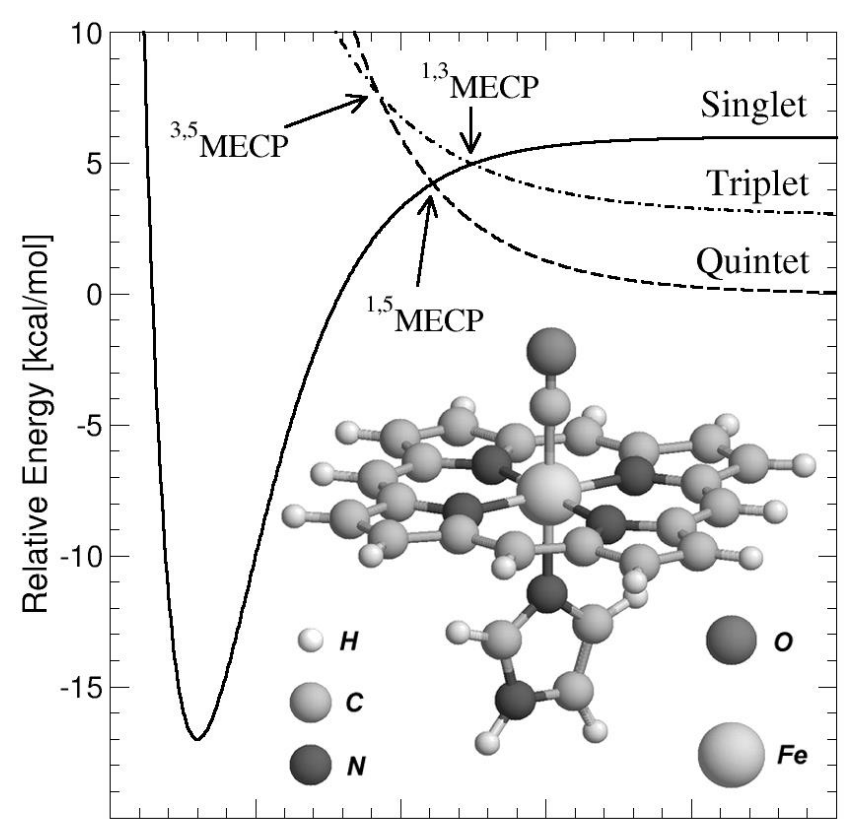

Reaction Coordinate 